Energy and Sustainability VIII 87

\title{
COMPARISON OF POTENTIAL MATERIALS FOR PRODUCER GAS WET SCRUBBING IN PILOT-SCALE GASIFICATION UNIT
}

\author{
JAKUB ČESPIVA, JAN SKŘÍNSKÝ \& JÁN VEREŠ \\ VŠB - Technical University of Ostrava, Czech Republic
}

\begin{abstract}
The wet scrubber technology for tar content decrease can bring a necessary cleaning solution for the biomass gasification product syngas. This paper investigates and compares several materials suitable for a tar capture. The scrubbing liquids were easily accessible and economically affordable liquids, some of which are known to possess a solving effect on the tar compounds. There are two organic chemicals: acetone and propane-2-ol, demineralised water and, as a representative of oily substances, rhodorsil oil. The investigation was divided in two parts. The first part was a producer gas partial online sampling through a set of five impinger bottles, each filled with $100 \mathrm{ml}$ of the investigated material. In the second part of the investigation, all samples underwent a laboratory analysis, the results of which had given information about the trapped tar content after the sampling. The analysis consisted of weight difference, ultimate tar content and tar solvency activity examining. Of the tested scrubbing liquids, acetone showed a good capturing activity of tar, which was around $7.7 \mathrm{~g} \cdot \mathrm{m}^{-3}$. Even better results were detected in the case of propane-2-ol where $12.5 \mathrm{~g} \cdot \mathrm{m}^{-3}$ was captured. On the other hand, water showed no solving activity and the tar capture rate was significantly lower - that is, $1.2 \mathrm{~g} \cdot \mathrm{m}^{-3}$. Surprisingly, similar results occurred in the case of rhodorsil oil. The downside of the materials with good solubility is a high evaporation tendency, which may complicate their final practical usage. The presented values in this paper are related to normal conditions of wet gas (temperature of $273.15 \mathrm{~K}$; pressure of $101,325 \mathrm{~Pa})$.
\end{abstract}

Keywords: wet scrubbing, scrubbing liquids, tar, tar removal, gasification, biomass, comparison.

\section{INTRODUCTION}

The issue of global weather changes associated with anthropogenic sources of carbon dioxide and other substances is an often discussed topic worldwide. Following that, the demand for green energy and alternative fuels is ever growing. One of the important sources of alternative fuel could be biomass gasification. Its product, syngas, contains mainly $\mathrm{CO}, \mathrm{H}_{2}, \mathrm{CH}_{4}, \mathrm{C}_{\mathrm{x}} \mathrm{H}_{\mathrm{y}}$, $\mathrm{O}_{2}, \mathrm{CO}_{2}$ (if autothermal gasification) and $\mathrm{N}_{2}$ (if air gasification). After a separation treatment valuable synthetic gas, consisting of $\mathrm{CO}$ and $\mathrm{H}_{2}$, is obtained.

However, before well-developed commercial use of gasification units, several technical issues have to be resolved. One such issue is the formation of pollutants, contained within the producer gas. Among these pollutants, tar compounds above all cause critical technical complications during the operation which could lead to an undesired shutdown of the technology.

Formation of tar compounds represents one of the greatest difficulties during the gasification process of the pilot small-scale experimental gasification facility at the Energy Research Center (ERC), VSB - Technical University of Ostrava, Czech Republic. These tar compounds are produced in $0.3-10.5 \mathrm{~g} \cdot \mathrm{m}^{-3}$ amounts during the operation of the unit [1].

Chłond [2], in his work, finds tar formation of BTX (benzene, toluene and xylene) at a rate of $10.1 \mathrm{~g} \cdot \mathrm{m}^{-3}$ and heavier tars at a rate of $10.4 \mathrm{~g} \cdot \mathrm{m}^{-3}$ during the gasification of spruce pellets. While the gasification temperature was equal to $750^{\circ} \mathrm{C}$, the overall tar formation rate was over $20 \mathrm{~g} \cdot \mathrm{m}^{-3}$, according to Chłond [2]. Similar results were obtained in other samplings, 
where a mixture of residue derived fuel (RDF) and wood pellets was used at the same temperature.

Heavy hydrocarbons, primarily defined as tar, officially include all the condensable organic hydrocarbons which have a higher dew point (or alternatively higher molecular weight) than benzene [3]. Fig. 1 shows a typical composition of the biomass tar compounds. The values are approximate as the composition varies depending on the gasification conditions and fuel properties [3], [4].

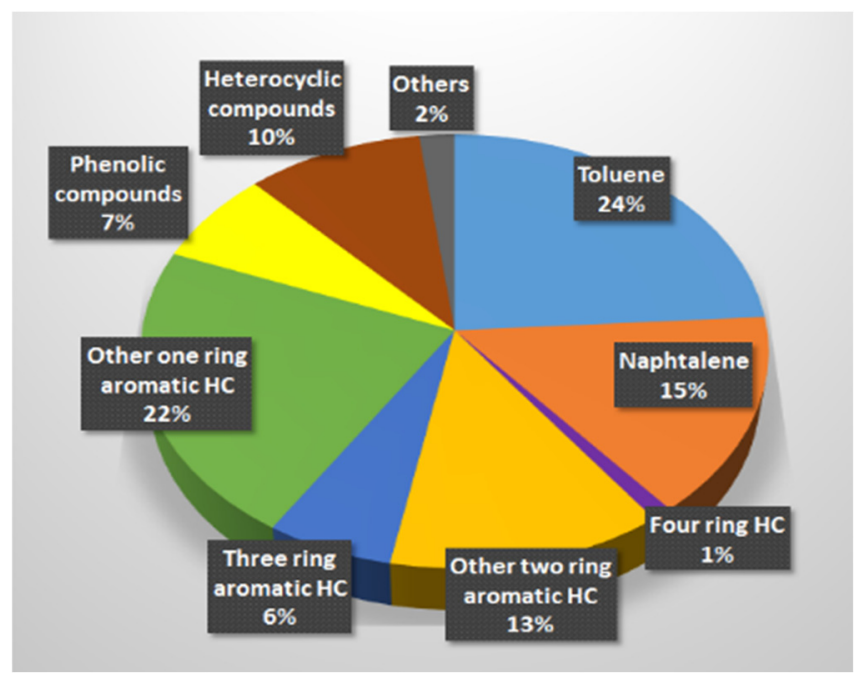

Figure 1: Typical composition of biomass tars [4].

The large amount of tar definitions and measurement methods, as well as the wide spectrum of organic compounds, makes it almost impossible to capture tars with a clear definition. There are hundreds of tar compounds that have significant differences between them. But a main categorization can be adopted according to their principal characteristics, their detectability and the number of aromatic rings in their molecules. The Energy Research Centre of The Netherlands (ECN) defines the tar classes as seen in Table 1 [5], [6].

Tars can be corrosive and can cause clogging and disrupt the operation of pyrolysis and gasification plants [3]. As the tar is a highly viscous matter, solid particles can adhere to the surface and speed up the clogging process. Another reason to clean the producer gas of all tar compounds is its further usage in the ERC Fischer-Tropsch liquefaction synthesis technology, which is very sensitive to impurities of any form. Therefore, the removal of tar is crucial also from this point of view.

There are many ways to remove these environmentally hazardous pollutants using primary and secondary tar removal methods, according to the placement. While the primary methods decrease tar production itself, the secondary methods deal with tars already produced. Ahrenfeldt and Knoef [7] categorise secondary pollutants' removal methods as: cyclone filters, barrier filters, electrostatic precipitators (ESP) and wet scrubbers. For tar removal specifically it is wet scrubbers, ESP and catalytic conversion (primary or secondary). Both ESP and catalytic conversion tar decomposition approaches require significant technological improvements, investments and space demands to any existing or brand new gasification facility. 
Table 1: Tar classification [5].

\begin{tabular}{|c|l|l|l|}
\hline Class & Type & Description & Examples \\
\hline 1 & $\begin{array}{l}\text { Gas chromatography } \\
\text { undetectable }\end{array}$ & - & Biomass fragments \\
\hline 2 & Heteroclytic compounds & $\begin{array}{l}\text { These are components that } \\
\text { generally exhibit high water } \\
\text { solubility. }\end{array}$ & $\begin{array}{l}\text { Phenol, cresol, } \\
\text { quinoline, pyridine }\end{array}$ \\
\hline 3 & Aromatic components & $\begin{array}{l}\text { Light hydrocarbons, which } \\
\text { are important from the point } \\
\text { view of tar reaction } \\
\text { pathways, but not in } \\
\text { particular towards } \\
\text { condensation and solubility. }\end{array}$ & $\begin{array}{l}\text { Toluene, xylene, } \\
\text { styrene ethylbenzene } \\
\text { (excluding benzene) }\end{array}$ \\
\hline 4 & $\begin{array}{l}\text { Light polyaromatic } \\
\text { hydrocarbons }(2-3 \text { rings }\end{array}$ & $\begin{array}{l}\text { These components } \\
\text { condense at relatively high } \\
\text { concentrations and } \\
\text { intermediate temperatures. }\end{array}$ & $\begin{array}{l}\text { Naphthalene, } \\
\text { indene, biphenyl, } \\
\text { anthracene }\end{array}$ \\
\hline 5 & $\begin{array}{l}\text { Heavy polyaromatic } \\
\text { hydrocarbons }(>3 \text { rings } \\
\text { PAHs })\end{array}$ & $\begin{array}{l}\text { These components } \\
\text { condense at relatively high } \\
\text { temperature at low } \\
\text { concentrations. }\end{array}$ & $\begin{array}{l}\text { Fluoranthene, } \\
\text { pyrene, crysene }\end{array}$ \\
\hline 6 & $\begin{array}{l}\text { GC detectable, not } \\
\text { identified compounds }\end{array}$ & - & Unknowns \\
\hline
\end{tabular}

The wet scrubber solution provides a physical removal of tar compounds using a scrubber unit working with ideal scrubber liquid. In the scrubber, particles are collected by a collision with droplets of the scrubber liquid [7]. Such liquid could be demineralised water, but also other, lipophilic material with solving effect such as those which were tested in this paper in order to be used with better overall removal efficiency.

Nakamura et al. [8] claims 96\% tar removal efficiency using bio-oil scrubber coupled with char filtration section. Oil alone, if new, would work with $64.5 \%$ efficiency at a temperature of $50^{\circ} \mathrm{C}$. Other authors describe venturi scrubber technology to remove tar from the producer gas with $50-90 \%$ removal efficiency. Often used material for such technology in industry is a rapeseed methyl-ester (RME) oil [9], [10].

The downside of scrubbing technology (e.g. water scrubbing) is the sorbent contamination. The waste liquid cannot be discharged to the environment without chemical and/or biological waste water treatment and usually requires additional treatment facilities. An interesting solution is the warm gas clean process, which operates with temperatures above the scrubber liquid dew point but below the condensation temperature of most tars. This provides lower scrubber material cost and less intensive waste liquid treatment [7], [8], [11].

\section{MATERIALS AND METHODS}

\subsection{Description of gasification regime and conditions}

The gasification process was realized in a fixed bed counter-current reactor. The regime of the process was autothermal; the gasification reactor obtained the heat for the chemical 
reactions directly from the partial combustion reactions themselves instead of an outer heat source. The gasification media was ambient air without preheating.

The reactor is a small-scale pilot unit working with power up to $100 \mathrm{~kW}$. The shape of the grate is circular, designed for wood pellets of a diameter around $5 \mathrm{~mm}$ and length no more than $30 \mathrm{~mm}$. These pellets were used as a fuel in this experiment. From the fuel storage they were led and piled above the grate by two synchronized screw conveyors (horizontal and vertical). The fuel consumption was approximately $40 \mathrm{~kg} \cdot \mathrm{h}^{-1}$. The producer gas was generated with an average flow of $56 \mathrm{~m}^{3} \cdot \mathrm{h}^{-1}$. During the whole experiment, the temperature within the reactor was held in a range from 700 to $800^{\circ} \mathrm{C}$. This temperature range is typical for producing high amount of polluting tar particles in this reactor.

The examples of the chemical composition of producer gas for Rhodorsil oil and Acetone are shown in Figs. 2 and 3, respectively. The overall average values of the dry producer gas composition during the experiment was $\mathrm{H}_{2} 7 \%, \mathrm{CO} 22 \%, \mathrm{CO}_{2} 9 \%, \mathrm{CH}_{4} 4.5 \%$, $\mathrm{CnHm} 0.5 \%$, $\mathrm{O}_{2} 2 \%, \mathrm{~N}_{2} 55 \%$, according to the data from portable gas analyser [1], [2].

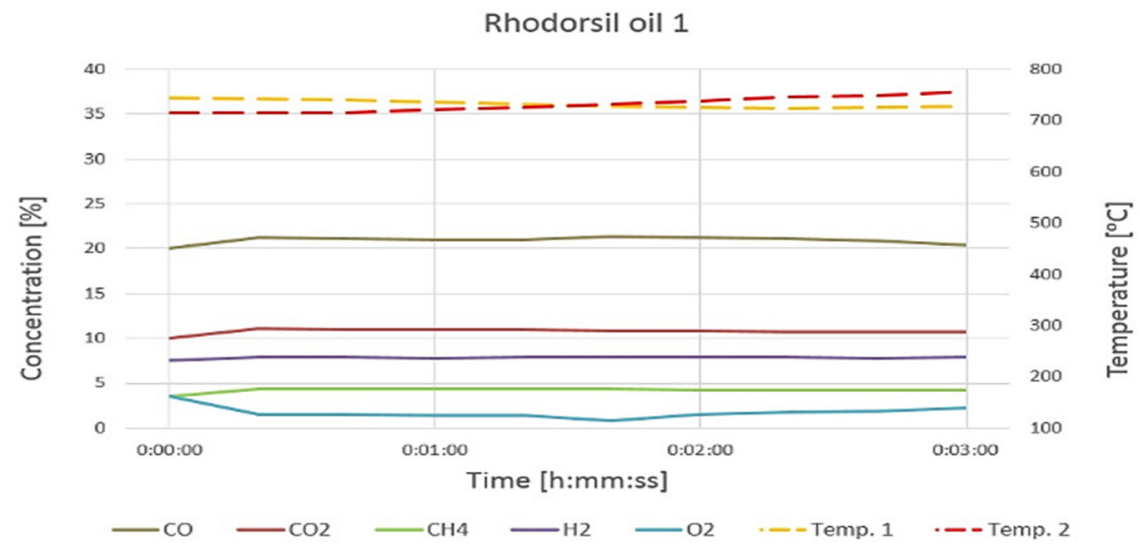

Figure 2: Producer gas chemical composition example - Rhodorsil oil 1.

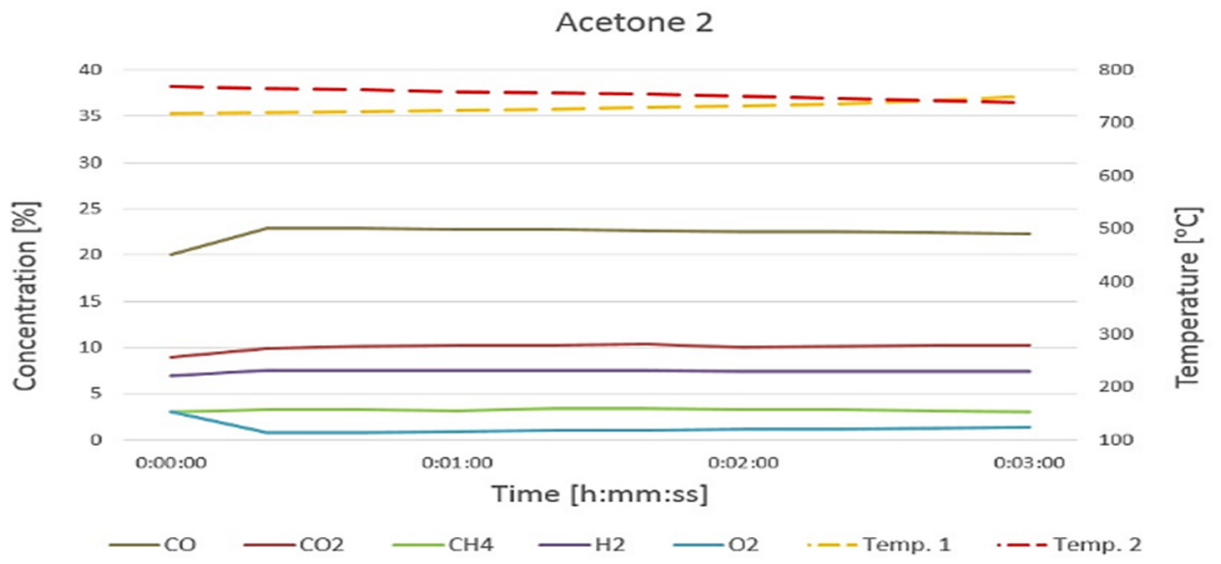

Figure 3: Producer gas chemical composition example - Acetone 2. 


\subsection{Scrubbing liquids description}

As mentioned above, among the tested cleaning materials for sufficient tar removal, there were acetone (dimethyl ketone), propan-2-ol (also known as isopropyl alcohol, isopropanol or 2-propanol), rhodorsil oil based on siloxane chains and demineralised water. Acetone, as well as propan-2-ol, is known for good cleaning activity of tar stained surfaces. Their polarity is close to that of most organic compounds which makes them proper tar solvents.

Oils are materials often used in wet scrubber technology for flue gas treatment and so the effect of rhodorsil oil on tar treatment was investigated in this paper. The last liquid to be tested in comparison was demineralised water. The solubility of tars in water is very low, but because water is easily accessible, it is also included among the scrubbing liquids. A detailed description of the scrubbing liquids and their properties is listed in Table 2.

Table 2: Properties of scrubbing liquids for $20^{\circ} \mathrm{C}$.

\begin{tabular}{|l|c|c|c|c|c|}
\hline Material & $\begin{array}{c}\text { Purity } \\
(\%)\end{array}$ & $\begin{array}{c}\text { Chemical } \\
\text { formula }\end{array}$ & $\begin{array}{c}\text { Molar mass } \\
\left(\mathrm{g} \cdot \mathrm{mol}^{-1}\right)\end{array}$ & $\begin{array}{c}\text { Density } \\
\left(\mathrm{kg} \cdot \mathrm{m}^{-3}\right)\end{array}$ & $\begin{array}{c}\text { Boiling point } \\
\left({ }^{\circ} \mathrm{C}\right)\end{array}$ \\
\hline Acetone [13] & 99.5 & $\mathrm{C}_{3} \mathrm{H}_{6} \mathrm{O}$ & 58.08 & 786 & 56 \\
\hline Propane-2-ol [14] & 99.5 & $\mathrm{C}_{3} \mathrm{H}_{8} \mathrm{O}$ & 60.10 & 785 & 82 \\
\hline Demi. water [15] & 100.0 & $\mathrm{H}_{2} \mathrm{O}$ & 18.02 & 998 & 100 \\
\hline Rhodorsil oil [16] & 100.0 & - & - & 959 & $280^{* *}$ \\
\hline
\end{tabular}

$* 25^{\circ} \mathrm{C} ; * *$ flash point.

\subsection{Sampling}

The sampling of the gas was realized through a sampling point situated on the pipeline right after the reactor. The suction rate was equal to $111 \cdot \mathrm{min}^{-1}$. The sampling was done by a heated probe with a ceramic filter to capture solid particles from the producer gas. After the probe followed a set of five impinger bottles filled with the tested liquid. Each bottle contained 100 $\mathrm{ml}$ and was emerged in water/salt/ice mixture to keep the ambient temperature close to $0^{\circ} \mathrm{C}$.

Each sampling was terminated after an interval of 3 minutes and bottle contents were mixed together. This was done twice for each material, making eight 0.51 samples (two for each material) suitable for further laboratory investigation.

After the sampling impinger bottles train, another set of similar bottles followed. Those were filled with additional cleaning liquid and placed in the freezing environment in order to protect the membrane pump, flowmeter and chemical composition analyser Pollutec Gas Analyser $3000 \mathrm{p}$. This analyser works with $11 \cdot \mathrm{min}^{-1}$ and detects all important components from the analysed gas using a dual beam nondispersive infrared detector (NDIR), a thermal conductivity detector (TCD) and an electrochemical detector (ECD). The schematic diagram of the sampling track is shown in Fig. 4. The sampling train was set and installed according to CEN technical specification for tar sampling [12]. 


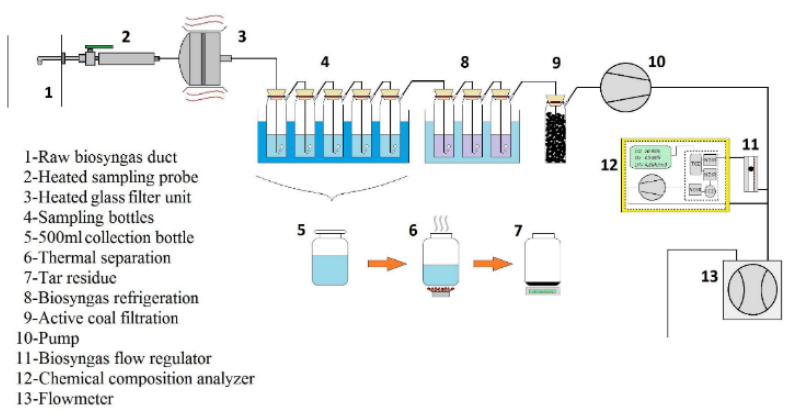

Figure 4: Tar sampling track.

\subsection{Tar content investigation}

Prior to the sampling, the weight of the filled bottles was checked on Kern DE $12 \mathrm{~K} 1 \mathrm{~N}$ measuring device and recorded for later weight difference analysis. After each experiment period of 3 minutes, the sampling probe was closed and the pump stopped. The sampling impinger bottles were then detached from the train in order to maintain the weight difference analysis. This analysis provided information about weight change associated with increased tar content trapped within the cleaning material.

In the second step, the collection bottle with the tested liquid was attached to a laboratory distillation column where the examined material was separated to leave only the residue tar behind.

In the last step to investigate the sufficiency of the cleaning materials, their solubility was examined. The tar solubility test consisted of basic tar/solvent mixing. During the test, the exposition of visible tar matter within the scrubbing liquid was measured. The time needed for a complete solvency of tar matter is directly proportional to the solubility of the material.

\section{RESULTS AND DISCUSSION}

\subsection{Results}

The investigation of tar capture ability of chosen liquid materials consisted of three separated parts; weight analysis, evaporation tar residue analysis and tar solvency analysis. All materials' investigations were done in this order: Acetone 1 - propan-2-ol 1 - demineralised water 1 - rhodorsil oil 1 - acetone 2 - propan-2-ol 2 - demineralised water 2 - rhodorsil oil 2.

The results of weight records were unexpected. Demineralised water and rhodorsil oil have shown a weight increase of $1.3 \mathrm{~g} \cdot l^{-1} \cdot \mathrm{min}^{-1}$ on average. In the case of solvent materials, a weight decrease was observed. The weight of propan-2-ol was lower by $1.4 \mathrm{~g} \cdot \mathrm{l}^{-1} \cdot \mathrm{min}^{-1}$ on average, while that of acetone dropped by $16 \mathrm{~g} \cdot l^{-1} \cdot \mathrm{min}^{-1}$ on average. This phenomenon can be explained by evaporation of the materials, which tend to evaporate at lower temperatures than water or oil (see Table 2).

This theory was proved by examining the content increase in additional refrigeration bottles, following after the sampling train. Both water and oil samples did not change the volume of the freezing impinger bottles' content. The problem with the evaporation could be solved by condensation surfaces, that is, mist eliminators, placed above the scrubber to avoid evaporated material to escape the unit. 
According to materials safety data sheet (MSDS), both acetone and propan-2-ol are considered non-hazardous materials for the environment and o-zone layer with good biodegradability in water and soil. They do not cause a greenhouse effect and are recycled by distillation. However, it is in our best interest to keep away from possible environment contamination and from contact with human skin, eyes and respiratory tract where it may cause serious irritation. Another reason to apply mist eliminators is the exposure limits which are 2,500 $\mathrm{mg} \cdot \mathrm{m}^{-3}$ in the case of acetone and $980 \mathrm{mg} \cdot \mathrm{m}^{-3}$ in the case of propan-2-ol, according to the Occupational Safety and Health Administration (OSHA). Acetone and propane-2-ol are flammable and explosive liquids and their usage is temperature limited [13], [14].

Due to insufficient results obtained from weight analysis, a more detailed investigation of tar content was necessary. This was done with a distillation column, part of which was a water bath with adjustable temperature. Each of the $500 \mathrm{ml}$ samples was in the rotating test-glass, emerged in the water bath and connected to the distillation column. Vapours then condensed in this water-cooled column and leaked off. The result of this process was a separated tar matter within the test-glass, the weight of which was analysed. The distillation of the materials was held in two steps.

In the first step, water bath temperature was adjusted below the material boiling point to separate lighter tars like cyclohexane. Then, the temperature was raised above the boiling point of the material to evaporate it. After the evaporation of the scrubbing liquid, only heavier tars remained within the test-glass. According to Table 2, the bath temperature was set above $57^{\circ} \mathrm{C}$ to evaporate acetone, $83^{\circ} \mathrm{C}$ to evaporate propane-2-ol and $101^{\circ} \mathrm{C}$ to evaporate water. The separation of rhodorsil oil in this way was not possible in the lab-scale conditions.

The last test was aimed on the tar solubility of the scrubbing liquids. In this test, $0.05 \mathrm{~g}$ of very fine and homogenised fraction of the solid tar, collected from the technology pipeline, was solved in $150 \mathrm{ml}$ of each material. The mixture was gently stirred and the time, needed for a complete visible dissolution of the tar, was measured. The fastest dissolution was measured in acetone - $60 \mathrm{~s}$ approximately. Propan-2-ol solved the tar powder five times slower while demineralised water and rhodorsil oil had no visible solving effect on the tar.

In addition, a $50 \%$ mixture of water and acetone was examined as well. Such mixture is also a potential solution for the tar removal. The result of approximately $180 \mathrm{~s}$ confirmed that water behaves as tar solvency restraint but could positively affect the evaporation disadvantage of acetone or propan-2-ol. Fig. 5 shows the samples examined for tar solving effect. The results of all three analyses are presented in Table 3.

A

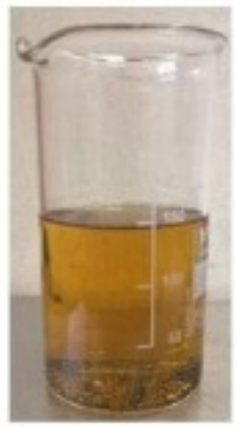

B

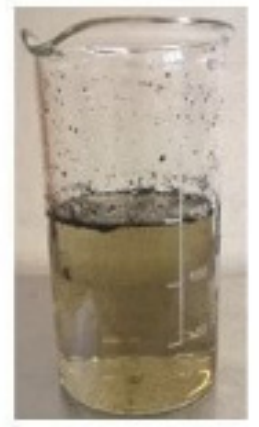

C

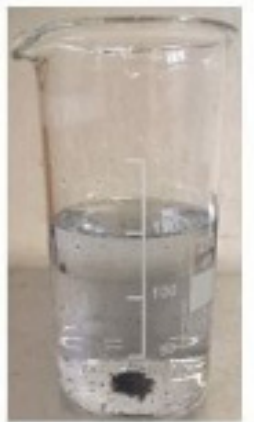

Figure 5: Tar solving samples. (A) Acetone; (B) Acetone/water; and (C) Water. 
Table 3: Average results of the comparing analyses.

\begin{tabular}{|l|c|c|c|}
\hline Material & $\begin{array}{c}\text { Weight } \\
\text { analysis }\end{array}$ & Tar analysis & $\begin{array}{c}\text { Solubility analysis } \\
(0.05 \mathrm{~g} \text { in } 150 \mathrm{ml})\end{array}$ \\
\hline & $(\mathrm{g})$ & $\left(\mathrm{g} \cdot \mathrm{m}^{-3}\right)$ & $(\mathrm{s})$ \\
\hline Acetone & -16.0 & 7.7 & 60 \\
\hline Propane-2-ol & -1.4 & 12.5 & 300 \\
\hline Demin. Water & 1.3 & 1.2 & $>1,600$ \\
\hline Rhodorsil oil & 1.3 & $<1.3$ & $>1,600$ \\
\hline
\end{tabular}

\subsection{Discussion}

At this point it is necessary to mention several important factors which may, in some way, affect the results of these experiments. First of all, gasification is a complex process, much dependent on many circumstances including temperature, pressure, oxidant activity, fuel properties etc. Especially in the case of fixed bed reactors it is difficult to keep the process stable and in desired deviation throughout long periods of time. The producer gas content may change and the scrubber technology demands may vary during the operation.

Other issues concern the sampling and scrubbing liquids; the efficiency of scrubbing materials decreases in time. During the scrubbing process, particles and solid contaminates would be accumulated in the absorbent, where these impurities obstruct the absorption mechanism, leading to decreased tar removal efficiency [10]. Therefore, a regeneration of the material would be necessary and must be taken into consideration in order to choose the most suitable scrubbing material.

According to previous studies, oils are often used materials for wet scrubbing to clean the producer gas. In the case of rhodorsil oil, the results were not better than in the case of other tested liquids, however, the analysis was inaccurate due to the physical properties of this oil.

Apart from technical oils, some authors successfully tested bio, vegetable (e.g. soybean or canola oil) and waste-cooking oils, however, polluted oil treatment is still a big issue for the gasification technology. Evaporable material with boiling point below that of tars could bring an interesting solution to the tar removal problems. Such approach would turn a downside of acetone or propan-2-ol into an advantage and have smaller impact on the environment, but the economical factor would remain an issue [8], [17].

As seen in Table 3, acetone and propane-2-ol are reliable solvents and absorbers of the tar compounds but with a tendency to evaporate while working in hot environment. This problem must be sufficiently solved technically in order to use these materials for producer gas scrubbing. A vapour condensing unit and evaporation itself must be examined in future studies, as well as usage of other materials or their combinations. This could lead to better overall and economic efficiency of the tar removal as acetone and propan-2-ol are both promising materials but could hardly work in pure state.

\section{CONCLUSION}

The tar removal from gasification generated producer gas, using four different scrubber liquids, was investigated and compared in this paper. The investigation was held through three-step analysis. The results have shown the complexity of acetone and propan-2-ol usage caused by their high evaporation rate. On the other hand, these materials proved to be very good solvents of tar compounds and to be capable of absorbing them well, up to ten times better than rhodorsil oil or demineralised water. However, for practical usage of acetone or 
propan-2-ol in wet scrubber technology, a demister or condensing unit must be applied in order to avoid exceeding evaporation.

The subject of the following study will focus on a combination of scrubbing liquids for obtaining the best results. The results of the analyses will serve as a basis for further technological proposal for wet scrubber technology construction in a pilot-scale biomass gasification unit in ERC.

\section{ACKNOWLEDGEMENTS}

This work was prepared within the project "Innovation for Efficiency and Environment - Growth", identification code LO1403 with the financial support from the Ministry of Education, Youth and Sports in the framework of the National Sustainability Programme I. This article was also prepared within the project SP2019/89 "Research of conversion processes and utilization of waste heat in the framework of fuel-energy technological complexes".

\section{REFERENCES}

[1] Ochodek, T. \& Najser, J., Zplyňování biomasy I, Ostrava: Výzkumné energetické centrum, pp. 74-80, 2014. (In Czech.)

[2] Chłond, R.A., Zvyšování výhřevnosti a kvality plynu ze zplyňování biomasy, $\mathrm{PhD}$ thesis, Ostrava: VŠB - Technical University of Ostrava, 2012. (In Czech.)

[3] Neeft, J.P.A., Knoef, H.A.M. \& Onaji, P., Behavior of Tars in Biomass Gasification Systems: Tar Related Problems and Their Solutions, Novem EWAB Program Report 9919, MHP Management Services, 1999.

[4] Shen, Y. \& Yoshikawa, K., Recent progresses in catalytic tar elimination during biomass gasification or pyrolysis - A review. Renewable and Sustainable Energy Reviews, 21, pp. 371-392, 2013.

[5] Bergman, P.C.A., Paasen, S.V.B. \& Boeriggter, H., The novel "OLGA" technology for complete tar removal from biomass producer gas. Pyrolysis and Gasification of Biomass and Waste, 2002

[6] Vakalis, S., Patuzzi, F., Moustakas, K., Sotiropoulos, A., Malamis, D. \& Baratieri, M., Analysis of tar compounds and quantification of naphthalene from thermal treatment of household biowaste. Journal of Environmental Management, 216, pp. 153-159, 2018.

[7] Ahrenfeldt, J. \& Knoef, H.A.M., Handbook Biomass Gasification, BTG Biomass Technology Group: Enschede, 2005.

[8] Nakamura, S., Kitano, S. \& Yoshikawa, K., Biomass gasification process with the tar removal technologies utilizing bio-oil scrubber and char bed. Applied Energy, 170, pp. 186-192, 2016.

[9] Hasler, P. \& Nussbaumer, T., Gas cleaning for IC engine applications from fixed bed biomass gasification. Biomass and Bioenergy, 16(6), pp. 385-395, 1999.

[10] Unyaphan, S., Tarnpradab, T., Takahashi, F. \& Yoshikawa, K., An Investigation of Low Cost and Effective Tar Removal Techniques by Venturi Scrubber Producing Syngas Microbubbles and Absorbent Regeneration for Biomass Gasification. Energy Procedia, 105, pp. 406-412, 2017.

[11] Woolcock, P.J. \& Brown, R.C., A review of cleaning technologies for biomass-derived syngas. Biomass and bioenergy, 52, pp. 54-84, May 2013.

[12] CEN Technical Specification, Biomass Gasification - Tar and Particles in Producer Gases - Sampling and Analysis, prepared by CEN task force BT/TF 143 WI CSC 03002.4TC, 2005. 
96 Energy and Sustainability VIII

[13] LabChem. Materials safety data sheet: Acetone. www.labchem.com/tools/msds/msds/LC10420.pdf. Accessed on: 1 Mar. 2019.

[14] LabChem. Materials safety data sheet: Isopropyl Alcohol (2-Propanol). www.labchem.com/tools/msds/msds/LC15750.pdf. Accessed on: 1 Mar. 2019.

[15] LabChem, Materials safety data sheet: Isopropyl Alcohol (2-Propanol). www.labchem.com/tools/msds/msds/LC26750.pdf. Accessed on: 1 Mar. 2019.

[16] Rhodorsil Oils 47 V 50 až 47 V 1000; Technical list; February 1996. (In Czech.) www.stavochemie.cz/tl/tl-rhodorsils.pdf.

[17] Paethanom, A., Nakahara, S., Kobayashi, M., Prawisudha, P. \& Yoshikawa, K., Performance of tar removal by absorption and adsorption for biomass gasification. Fuel Processing Technology, 104, pp. 144-154, 2012. 